\title{
Evaluation of Slippage Resistance of the Runway of the International Airport of Imam Khomeini
}

\author{
Shahin Shabani ${ }^{1}$, Shahrokh Zarei ${ }^{*}$
}

Dept. of Civil Engineering-Road \& Transportation, North Tehran Center, Payame Noor Univ. (PNU), Tehran, Iran

*Correspondence should be addressed to Shahrokh Zarei, Dept. of Civil Engineering-Road \& Transportation, North Tehran Center, Payame Noor Univ. (PNU), Tehran, Iran; Tell: +989356349844; Fax: +982155678231; Email: zarei shahrokh110@yahoo.com.

\begin{abstract}
A layer of rubber surface in an aircraft will be separated by takeoff and landing in flight surfaces and these layers stick to the surface of the runway and by repetition, the thickness of these layers increases and improves lubrication and reduces the effect of signs on flight surfaces. In this paper, we prepared a diagrammatic presentation of test in the friction between eastern and western parts of the flight. Average values of friction of each of the three sections of the runway, in down stroke and up stroke, were measured once before tire removal operation and the second time after the tire relaxation and the exploitation rate index and minimum quality of flight surfaces were determined and then compared with the values and standards of the Federal Aviation Organization ICAO and international aviation regulations. The results show that the average coefficients of friction before removal of the tires, to the eastern part and the western part are 0.31 and 0.63 , respectively which are lower than standard rates in comparison with standard values. And along with removal of tires, according to the minimum number of daily landings in runway of Imam Khomeini airport friction test should be measured every 4 months. Also, after tire removal, friction test should be carried out again and average friction coefficients for eastern and western parts were measured to be 0.72 and 0.67 , respectively which were obtained after comparison with standard values.

Key words: Friction, Runway, Slip resistance.

Copyright (c) 2017 Shahin Shabani et al. This is an open access paper distributed under the Creative Commons Attribution License.

Journal of Civil Engineering and Materials Application is published by Lexis Publisher; Journal p-ISSN xxxx-xxxx; Journal e-ISSN 2588-2880.
\end{abstract}

\section{INTRODUCTION}

I

$\mathrm{n}$ general, mechanisms of friction and resistance against slippage are two main components of the properties of the surface (small and large tissues) and the properties of the tires of the vehicle the tissue of the surface are classified based on two parameters of wavelength and depth to four different surfaces of fine texture, coarse texture, great texture and roughness (1). Also, the improvement methods of slippage resistance are classified in three steps in terms of time: Before asphalt imprinting which includes choosing the suitable materials and correct mixture, during the execution which include using the new technology in spreading the asphalt and the third step is after exploitation and the time when slippage resistance is less than the regulations limit. Evaluation operation which monitors the surface before and after these steps is carried out in labs and the features which are evaluated include issues such as slippage resistance, depth of the texture, performance, safety and economic costs (2). Friction reduction is resulted from the removal of fine and coarse texture and, on the other hand, with the increased pavement life, frictional resistance level is reduced naturally and requires the reconstruction of the pavement surface texture (3). The friction force and friction coefficient in road vehicles is a nonlinear function of the amount of wheel slip, although they differ in the amount of friction coefficient (4).

\section{DEFINING THE PROBLEM GOALS OF THE STUDY}

In recent years, (especially in the present decade), there have been many researches about the pavement of airport runways, but the required techniques, guidelines and the features for testing and measuring the friction of airport 
runways have not been provided and more studies and documentations are required. Therefore in this research we try to study the minimum values and exploitation of runway friction based on the Federal Aviation Administration standards and international aviation organizations ICAO and Imam Khomeini airport is the sample for the study.

\section{RESEARCH BACKGROUND}

Research in the field of friction road surfaces in the past decade can be classified to the issues of the relationship of friction and transportation safety, friction and type and texture of the rubber surface, friction and tissue pavement surface, friction and impact of type of materials of pavement especially aggregates as well as the impact of weather conditions on pavement skid resistance. This section is a brief overview of some of these studies. Dogov et al (1970) showed that the friction between the tire and the road surface is a function of various parameters such as the movement of rolling and sliding wheels (5). Generally, the assessment of the friction focuses on the minimum requirements meaning wet road surface (6). Ichihara in Japan, by comparing the accidents before and after the approaches about the increase in friction, showed a $75 \%$ reduction in wet conditions and $32 \%$ reduction in wet condition of the pavement (6). Katsh showed in a research about the relationship between the slippage resistance and accident rate in Virginia State that accident rate has a direct relationship with the slippage resistance of the pavement and increase in the friction coefficient reduces the accident rates and in order to define this relationship, linear regression among these two parameters is used (7). Also, Wang and Flinch studied the friction and the features of pavement texture in Virginia for 6 years and concluded that temperature affects the annual and seasonal changes of friction in pavement surface (8). Transport Institute at Ohio State conducted a research on the relationship between the friction surface and the number of accidents in the wet pavement. This research was conducted in intersections with and without lights and the results showed that repairing the surface of the pavements increases the safety significantly (9). Mayora and Pina evaluated the effect of friction resistance on traffic safety in wet conditions. The results showed that by increasing the value of the SCRIM machine from less than 50 to over 60 , accident rate is reduced to $68 \%$ in wet conditions (10). Khasane showed in a research that temperature has a significant effect on slippage resistance (11). Ahadi and Shafiee Pour studied the emergence and improvement of increase in friction resistance by water pressure and evaluated and monitored the features of the surface of the pathway before and after this method. The results showed that using water pressure, improves the depth of coarse texture, and improves the fine texture of aggregates as good as new (12). Ameri and et al showed in a field study that by changing the particles of aggregates, frictional characteristics of asphalt mixture will change (13). Sodagari and et al evaluated the positive effects of micro-surfacing covering on slippage resistance in Tehran-Qom highway and evaluated the changes in slippage resistance in different parts of the highway before and after the coverage (14). Fakhri and et al showed in a study that statistics of accidents in Shahid Rajaee highway, Tehran have reduced by $25 \%$ after modifying the surface of pavement with asphalt coverage. Also, accidents in the second half of the year is about $70 \%$ compared to the whole year which indicates the effect of climate conditions and reduction in the reduction of slippage resistance of pavements by wetting the surface of the pavement (15). Amini et al modeled the effect of slippage resistance of the pavement on the abundance of accidents in intersection in cities without light and showed that by increasing the slippage resistance by $1 \%$, accident rates reduced by $7.5 \%$ in urban intersections (16). Mirabi and Akbari studied the effect of temperature on slippage resistance of different types of asphalt mixture in lab and concluded that by increase in temperature, the slippage resistance of different types of asphalt mixtures decreases (17). Sadeghi and et al suggested different static and dynamic models for estimating the friction force and tires and suggested a friction model of average focused Logger (18). Moaveni and Maleki presented a new relationship for defining the friction coefficient as an explicit function of longitudinal speed of the vehicle and angular velocity of the wheel directly, and proved the accuracy of the results by lab data (19). Ameri and et al evaluated the polished surface resistance in Iran and studied the behavior of aggregates and their resistance against polishing (20).

\section{METHODS FOR MEASURING FRICTION}

Friction models are divided to static and dynamic models. Static model creates a relationship between velocity and friction of the road and tires in a permanent state and dynamic model states the unstable behavior of the vehicle under a variable speed with time. Static devices of measuring the friction of pavement surface like English pendulum are not suitable due to having weak points including measuring the slippage resistance in a short distance and locally, stability of the speed of measurement and not considering the effect of the weight and type of the tire for field studies. In this research, STFT friction measurement device is used which is a dynamic friction measurement device. This device is designed for airport runways and cab runways but could be used for measurement in road surfaces. This device which is pulled by a standard vehicle with a specific velocity is planned for operational conditions and storage according to ICAO and US Federal Aviation Administration regulations and consists of a mechanical measurement tire on a trailer and STMC software system. This software is a computer measurement system, has a laptop with touchpad, is windows-based, can store unlimited data and is used for analysis and presentation of reports or sending and storing the data. In order to ensure the accuracy of measurement, the related software is calibrated for the condition of the 
airport.

According to the Federal Aviation Administration

\section{ACCEPTABLE LIMITS} standards, timeline of visiting and assessing the flight surfaces are planned as Table 1 .

Table 1. Duration of the friction of the surface of the flight (21)

\begin{tabular}{c|c}
\hline Minimum friction survey frequency & Number of daily minimum Turbo jet landings per runway end \\
\hline 1 year & Less than 15 \\
6 months & $16-30$ \\
3 months & $31-90$ \\
1 month & $91-150$ \\
2 weeks & $151-210$ \\
1 week & More than 210 \\
\hline
\end{tabular}

Timeline of the field evaluation of friction in flight surfaces are determined after determining the numbers of daily landings in Imam Airport and comparing them to the table above. Also according to the type of friction tester device, the required coefficients for determining the quality of flight surfaces are determined as Table 2.

Table 2. Limitations of friction in flight runways (21)

\begin{tabular}{|c|c|c|c|c|c|c|c|}
\hline \multirow{2}{*}{$\begin{array}{l}\text { Minimum friction } \\
\text { level }\end{array}$} & \multirow{2}{*}{$\begin{array}{l}\text { Maintenance } \\
\text { planning level }\end{array}$} & \multirow{2}{*}{$\begin{array}{l}\text { Design objective for } \\
\text { new surface }\end{array}$} & \multirow{2}{*}{$\begin{array}{l}\text { Test water depth } \\
(\mathrm{mm})\end{array}$} & \multirow{2}{*}{$\begin{array}{c}\text { Test } \\
\text { speed } \\
(\mathrm{km} / \mathrm{h})\end{array}$} & \multicolumn{2}{|c|}{ Test tire } & \multirow{2}{*}{ Test equipment } \\
\hline & & & & & $\begin{array}{c}\text { pressure } \\
(\mathrm{k} \mathrm{Pa})\end{array}$ & type & \\
\hline 0.42 & 0.52 & 0.72 & 1 & 65 & 70 & $\mathrm{~A}$ & \multirow{2}{*}{ Mu-meter Trailer } \\
\hline 0.26 & 0.38 & 0.66 & 1 & 95 & 70 & $A$ & \\
\hline 0.50 & 0.60 & 0.82 & 1 & 65 & 210 & $\mathrm{~B}$ & \multirow{2}{*}{ Skiddometer Trailer } \\
\hline 0.34 & 0.47 & 0.74 & 1 & 95 & 210 & $\mathrm{~B}$ & \\
\hline 0.50 & 0.60 & 0.82 & 1 & 65 & 210 & $\mathrm{~B}$ & \multirow{2}{*}{$\begin{array}{l}\text { Surface Friction } \\
\text { Tester Vehicle }\end{array}$} \\
\hline 0.34 & 0.47 & 0.74 & 1 & 95 & 210 & $\mathrm{~B}$ & \\
\hline 0.50 & 0.60 & 0.82 & 1 & 65 & 210 & $\mathrm{~B}$ & \multirow{2}{*}{$\begin{array}{l}\text { Runway Friction } \\
\text { Tester Vehicle }\end{array}$} \\
\hline 0.41 & 0.54 & 0.74 & 1 & 95 & 210 & $\mathrm{~B}$ & \\
\hline 0.48 & 0.57 & 0.76 & 1 & 65 & 210 & $\mathrm{~B}$ & \multirow{2}{*}{$\begin{array}{l}\text { TATRA Friction } \\
\text { Tester Vehicle } \\
\end{array}$} \\
\hline 0.42 & 0.52 & 0.67 & 1 & 95 & 210 & $\mathrm{~B}$ & \\
\hline 0.43 & 0.53 & 0.74 & 1 & 65 & 140 & $\mathrm{C}$ & \multirow{2}{*}{ GRIPTESTER Trailer } \\
\hline 0.24 & 0.36 & 0.64 & 1 & 95 & 140 & C & \\
\hline
\end{tabular}

Also, based on the international aviation institution ICAO standards, removal of tires is done experimentally and based on the number of the flights and is presented in Table 3.

Table 3. Removal of tires experimentally (22)

\begin{tabular}{c|c}
\hline $\begin{array}{c}\text { Number of daily turbojet aircraft landing per } \\
\text { runway end }\end{array}$ & $\begin{array}{c}\text { Suggested rubber deposit removal } \\
\text { frequency }\end{array}$ \\
\hline 2 years & Less than 15 \\
1 year & $16-30$ \\
6 months & $31-90$ \\
4 months & $91-150$ \\
3 months & $151-210$ \\
2 months & More than 210 \\
\hline
\end{tabular}

After measuring the friction, the results are compared to tire removal will be carried out. the data in Table 4 and Table 2 and then the operation of

\begin{tabular}{c|cc}
\multicolumn{2}{|c}{ Table 4. Provided friction of the surface (21) } \\
\hline Code & Estimated braking action & Measured coefficient \\
\hline 5 & good & 0.4 and above \\
4 & Medium to good & $0.36-0.39$ \\
3 & Medium & $0.3-0.35$ \\
2 & Medium to poor & $0.26-0.29$ \\
1 & Poor & 0.25 and below \\
\hline
\end{tabular}

After tire removal, friction is measured again and the quality of the tire removal will be evaluated

\section{METHODOLOGY OF THE RESEARCH}

In this research, after field study of the Imam Khomeini airport, two parts of the runways with the lengths of 800 meters from RWY 29R-11L and 500 meters from
RWY11L-29R runways are chosen and are separated into three parts. Then the status of friction in each part is evaluated using the device of measuring friction STFT. Based on the results and drawing of the friction diagrams of the visiting period, limitations of the friction of the runway and tire removal periods are classified. And the estimation of the function of the break has been measured 
based on friction level and the minimum level of exploitation from flight surfaces are measured and compared with the values of Federal aviation administration and ICAO standards and in the end, minimum number of daily landings in International Imam Khomeini airport, visiting periods and removal of tires are determined.

\section{RESULTS}

In this research, after measuring the friction by STFT device in different parts of the runway, the average value of measurements was considered as the basis. Also in order to determine the minimum number of daily landings, statistics of takeoffs and landings in three consecutive years were used according to Figure 1.

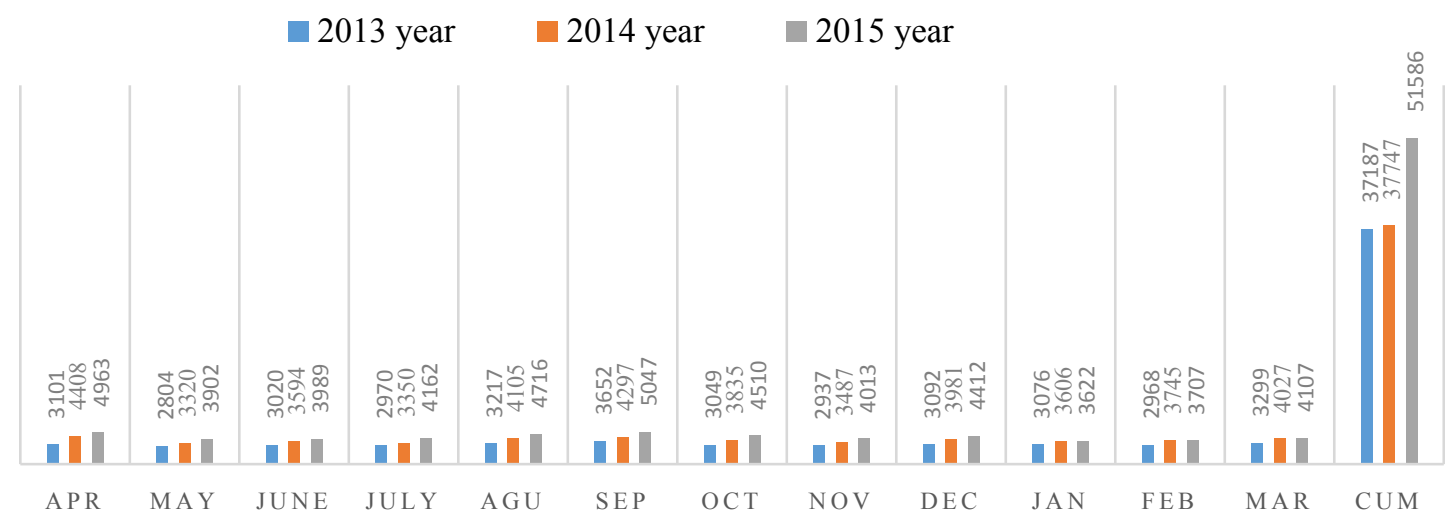

Figure 1. Takeoffs and landings in three consecutive years

According to the number of annual flights, average daily flights in Imam Khomeini airport for 2013 to 2015 was 115. Therefore according to the daily flights and by comparison with the values of Table 1 and Table 3 , the visiting period for testing the friction is 1 month and the period for tire removal is 4 months. In this paper, in addition to drawing the diagrams of friction tests for two eastern and western parts of flight surfaces, the average values of friction are measured in each part before and after the act of tire removal.

\subsection{Results before friction test}

Diagrams of friction test are presented along with average values for runways Rwy 29R-11L and Rwy 11L-29R before tire removal in Figure 2 and Figure 3.
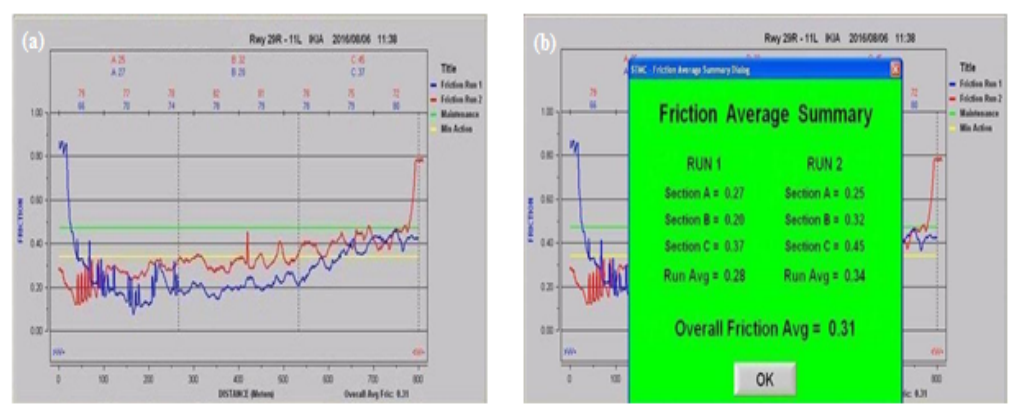

Figure 2. Diagrams of friction test of runway Rwy29R-11L (before tire removal); a): Diagram of friction test in runway Rwy29R-11L; b): Average value of friction in runway Rwy29R-11L
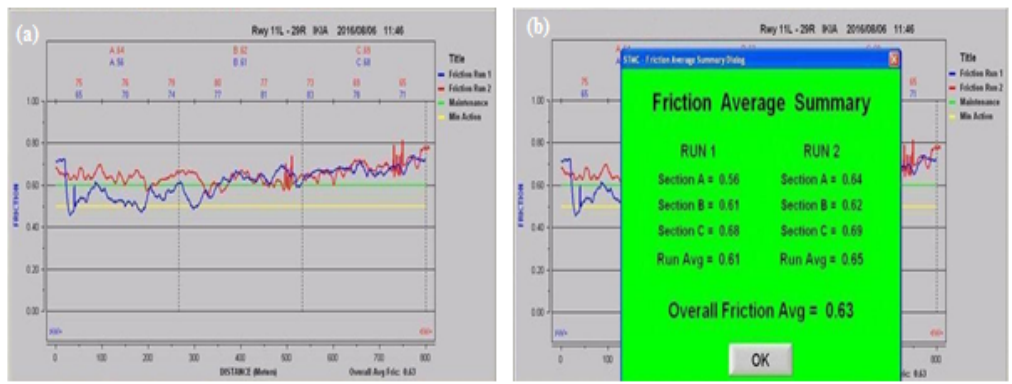

Figure 3. Diagram of friction test of runway Rwy11L-29R (before tire removal); a): Diagram of friction test in runway Rwy11L-29R; b): Average value of friction in runway Rwy11L-29R

\subsection{Results after friction test}

Diagrams of friction test are with average values for
Rwy29R-11L and Rwy 11L-29R after tire removal presented in Figure 4 and Figure 5. 


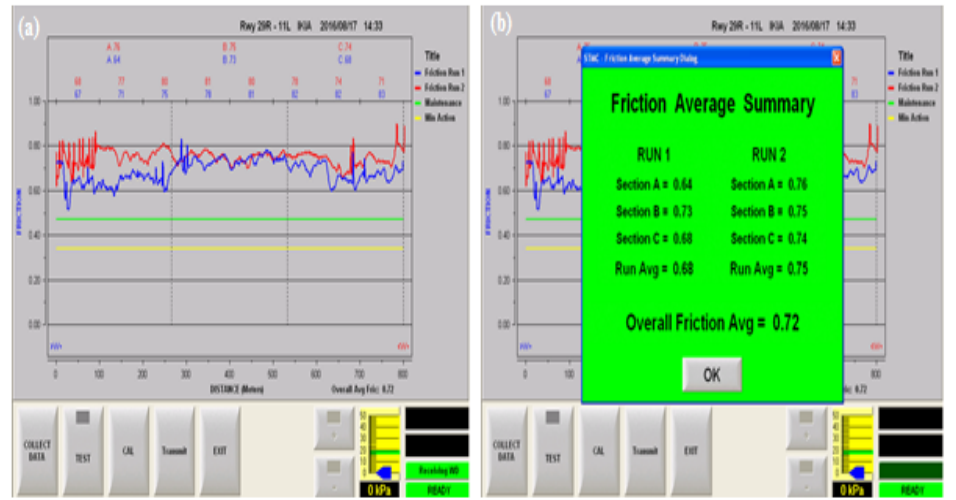

Figure 4. Diagrams of friction test for runway Rwy29R-11L(After tire removal); a): Diagram of friction test in runway Rwy29R-11L; b): Average value of friction in runway Rwy29R-11L
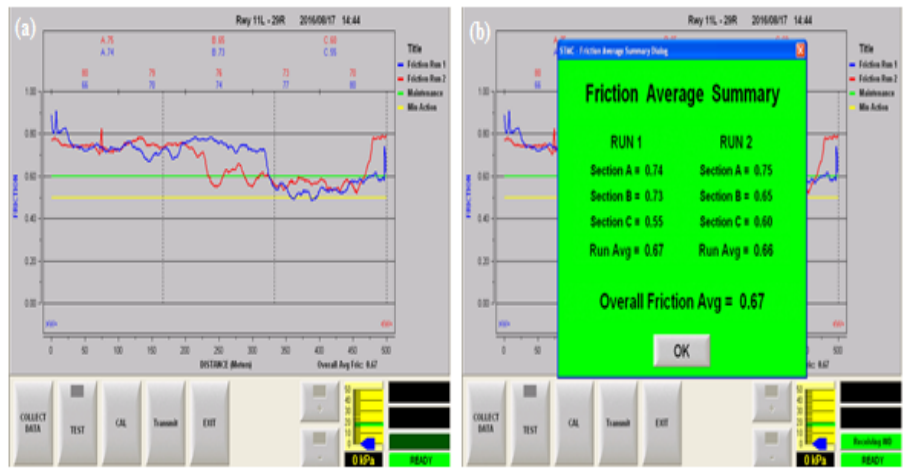

Figure 5. Diagram of friction test of runway Rwy11L-29R (After tire removal); a): Diagram of friction test of runway Rwy11L-29R; b): Average value of friction of runway Rwy11L-29R

\section{CONCLUSION}

Average friction coefficients before tire removal, for eastern and western part are 0.31 and 0.63 respectively, which are less than the standards and thus, tire removal is required. Average friction coefficients after tire removal for eastern and western part are 0.72 and 0.67 respectively by which the accuracy and quality of tire removal and sufficient friction of flight runways were assured. According to the values of friction test after tire removal, break operation provided for the surface is estimated to be good and is classified as code 5. According to the daily flight and comparing it to the standard value, visiting period for friction test is a month and tire removal period is 4 months.

\section{FUNDING/SUPPORT}

Not mentioned any Funding/Support by authors.

\section{ACKNOWLEDGMENT}

Not mentioned any acknowledgment by authors.

\section{AUTHORS CONTRIBUTION}

This work was carried out in collaboration among all authors.

\section{CONFLICT OF INTEREST}

The author (s) declared no potential conflicts of interests with respect to the authorship and/or publication of this paper.

\section{REFERENCES}

1. Testing ASf, Materials. Annual Book of ASTM Standards: ASTM; 2003. 2. Vaiana R, Praticò FG, luele T, Gallelli V, Minani V, editors. Effect of Asphalt Mix Properties on Surface Texture: an Experimental Study. Applied Mechanics and Materials; 2013: Trans Tech Publ.

3. Hall J, Smith K, Titus-Glover L, Evans L, Wambold J, Yager T. Guide for Pavement Friction Contractor's Final Report for National Cooperative Highway Research Program (NCHRP) Project 01-43. Transportation Research Board of the National Academies, Washington, DC. 2009.

4. Mirzaeinejad $\mathrm{H}$, Mirzaei M. A novel method for non-linear control of wheel slip in anti-lock braking systems. Control Engineering Practice. 2010;18(8):918-26

5. Dugoff $H$, Fancher $P$, Segel L. An analysis of tire traction properties and their influence on vehicle dynamic performance. SAE Technical Paper, 1970 0148-7191.

6. Hosking R. Road aggregates and skidding1992.

7. Kuttesch JS. Quantifying the relationship between skid resistance and we weather accidents for Virginia data. 2004.

8. Wang $\mathrm{H}$, Flintsch GW, editors. Investigation of Short-and Long-Term Variations of Pavement Surface Characteristics at the Virginia Smart Road. Transportation Research Board 86th Annual Meeting; 2007.

9. Larson RM, Hoerner TE, Smith KD, Wolters AS. Relationship between skid resistance numbers measured with ribbed and smooth tire and wet accident locations. 2008.

10. Mayora JMP, Piña RJ. An assessment of the skid resistance effect on traffic safety under wet-pavement conditions. Accident Analysis \& Prevention. 2009;41(4):881-6.

11. Khasawneh M, Liang RY. Temperature Effect on Frictional Properties of HMA at Different Polishing Stages. Jordan Journal of Civil Engineering. 2012;6(1):39-53

12. Kemp R. Investigates the effect of surface shear on pavements near road intersection. 2011.

13. Button JW, Perdomo D, Lytton RL. Influence of aggregate on rutting in asphalt concrete pavements. Transportation Research Record. 1990(1259). 14. Watanabe T, Fukui S, editors. A method for controlling tactile sensation of surface roughness using ultrasonic vibration. Robotics and Automation, 1995 Proceedings, 1995 IEEE International Conference on; 1995: IEEE.

15. Zhang $\mathrm{H}$, Ong $\mathrm{N}$, Lam $\mathrm{Y}$. Mold surface roughness effects on cavity filling of polymer melt in micro injection molding. The International Journal of Advanced Manufacturing Technology. 2008;37(11):1105-12.

16. Rezaei A. Development of a prediction model for skid resistance of asphalt pavements: Texas A \& M University; 2012.

17. Safavizadeh SA. Fatigue and fracture characterization of GlasGrid $₫$ reinforced asphalt concrete pavement: North Carolina State University; 2015. 
18. De Wit CC, Tsiotras $P$, editors. Dynamic tire friction models for vehicle traction control. Decision and Control, 1999 Proceedings of the 38th IEEE Conference on; 1999: IEEE.

19. Canudas-de-Wit C, Tsiotras $P$, Velenis $E$, Basset M, Gissinger G.

Dynamic friction models for road/tire longitudinal interaction. Vehicle System Dynamics. 2003;39(3):189-226.

20. Kermani MS, Safarzadeh M. Petrographic assessment of re-textured road surface aggregates. WIT Transactions on The Built Environment 2010;111:289-99.
21. Henry JJ. Evaluation of pavement friction characteristics: Transportation Research Board; 2000.

22. Kazda A, Caves RE. Airport design and operation: Emerald Group Publishing Limited; 2010. 